\title{
REFLEXIONES Y APORTES PARA PENSAR LA CULTURA EN LA ENSEÑANZA-APRENDIZAJE DE LENGUAS EXTRANJERAS
}

\section{REFLECTIONS AND CONTRIBUTIONS TO THINK ABOUT CULTURE IN A FOREIGN LANGUAGE TEACHING-LEARNING PROCESS}

\author{
Ana Liza Bugnone* \\ Verónica Cecilia Capasso**
}

\begin{abstract}
RESUMEN
En este artículo se analiza una perspectiva para pensar y aplicar contenidos de cultura en la enseñanza-aprendizaje de una lengua extranjera. Para ello, se presentan los presupuestos teóricos de los cuales partimos para concebir la relación entre lengua y cultura como un binomio y el vínculo entre interculturalidad y educación. Luego, se estudia el caso particular de la enseñanza de temas ligados a la cultura y la sociedad en una asignatura de un profesorado en portugués como lengua extranjera. Se plantea la forma en que en dicha materia se conciben teórica y metodológicamente los temas a dictar, enfatizando la necesidad de pensar de forma articulada la lengua y la cultura en el proceso de enseñanzaaprendizaje del portugués como lengua extranjera. Se ofrecen también algunos ejemplos que evidencian los modos de poner en práctica la perspectiva planteada, con el objeto de reflexionar sobre la misma y favorecer que sea tenida en cuenta en diversos ámbitos educativos donde se enseñe una lengua extranjera.
\end{abstract}

Palabras-clave: Cultura; lengua extranjera; portugués.

\section{ABSTRACT}

This article provides a perspective to think about and apply culture contents in the teaching and learning of a foreign language. To do this, we present our theoretical assumptions about the relationship between language and culture as a binomial and the link between interculturality and education. Then, we study the teaching of topics related to culture and society in a course that is part of a Teaching Portuguese as a Foreign Language university program. We describe the theory and methodology used by the teachers of this course in conceiving the topics to be taught, emphasizing the need to think about language and culture in an articulated way in the teaching-learning of Portuguese as a foreign language. We also give some examples of how to implement this perspective, in order to reflect on it and promote its consideration in the different educational settings where foreign languages are taught.

Keywords: Culture; foreign language; portuguese.

\footnotetext{
* Universidad Nacional de La Plata, Argentina. anabugnone@gmail.com

** Universidad Nacional de La Plata, Argentina. capasso.veronica@gmail.com
} 


\section{INTRODUCCIÓN}

En el presente artículo se desarrolla una perspectiva posible para pensar el lugar de la cultura en la enseñanza de una lengua extranjera, que parte de la importancia de incluir contenidos ligados a la cultura en materias específicas que ofrezcan una reflexión sobre contenidos teóricos y su aplicación, partiendo de las Ciencias Sociales. Para ello se realizará en primer lugar una presentación del tema, focalizando en la relación entre lengua, cultura e interculturalidad en términos conceptuales y en la necesidad de pensar de forma articulada la lengua y la cultura en el proceso de enseñanza-aprendizaje de una lengua extranjera. Asimismo, se destacará la importancia de reflexionar acerca de la forma en que se da el encuentro entre culturas de un modo democrático, lo que implica considerar las diferencias entre ellas como aspectos ineludibles. Luego, se analizará el caso específico de los modos de abordaje de los temas relacionados con la cultura y la sociedad en la enseñanza del Portugués como Lengua Extranjera en el marco de la cátedra "Cultura y sociedad" del Profesorado en Portugués de la Facultad de Humanidades y Ciencias de la Educación de la Universidad Nacional de La Plata (Argentina). Se presentará la propuesta metodológica de la que se parte y se verán, además, algunos ejemplos que resultan de las clases dictadas para evidenciar y poner en discusión los modos concretos y posibles de funcionamiento de los presupuestos que se desarrollan en la primera parte. Finalmente, se desarrollarán algunas reflexiones para dar cuenta de la experiencia y de la posibilidad de que sea tenida en cuenta en otros ámbitos educativos en los distintos niveles, tanto de portugués como de otras lenguas extranjeras.

Si bien ha sido destacada la importancia de añadir contenidos ligados a la cultura de la lengua objetivo, especialmente desde una visión centrada en la competencia sociolingüística, la cual señala que la falta de adecuación pragmática implica importantes problemas en la comunicación (MIQUEL, 1999), este artículo avanza hacia el estudio de un caso menos explorado. Se trata de la incorporación de contenidos teóricos de temas que parten de la Sociología y la Antropología que no solo incluyen información cultural para evitar malos entendidos o falta de adecuación, sino que se basan en la necesidad de promover la capacidad de análisis, reflexión y pensamiento crítico en los futuros profesores de lengua extranjera a partir del estudio de contenidos clave. Así, unidades de estudio ligadas a conceptos como la cultura, la sociedad, la identidad, el poder, el arte y sus aplicaciones concretas al caso de la sociedad en estudio, amplían la mirada sobre la interculturalidad en la enseñanza de lenguas extranjeras. De este modo, además de la información sobre la 
cultura en la que se desenvuelve la lengua en estudio -que es necesaria en las clases de lengua-, se amplía aquí al desarrollo de otros conocimientos para que los futuros profesores de lengua extranjera puedan reflexionar sobre temas referidos a la cultura y la sociedad, tanto de la lengua estudiada como de la propia. En este sentido, se propone complementar la visión del análisis comunicativo y pragmático de la lengua con una formación cultural más amplia y profunda que permita cuestionar la propia postura respecto del "otro", del sentido común, de lo dado como verdadero o esencializado y de los prejuicios, para dirigirse a un perspectiva democrática y consciente de las diferencias.

\section{EL BINOMIO LENGUA/CULTURA}

En los últimos años se ha revalorizado la combinación del estudio de una lengua y la enseñanza de temas vinculados con la cultura, la sociedad y la historia. Desde diferentes ángulos, se ha sostenido que una lengua no puede ser concebida en abstracto, en sus formalidades ajenas a cualquier referencia externa, contextual, situacional o cultural. En ese marco, la incorporación de aspectos que involucran una mirada desde las Ciencias Sociales en la enseñanza de una lengua parece ser cada vez más relevante.

En concordancia con lo dicho, para abordar el binomio lengua/cultura, concebimos a la cultura como trama de significaciones (GEERTZ, 1973). De esta forma,

Como sistemas entrelaçados de signos interpretáveis, a cultura não é um poder, algo ao qual podem ser atribuídos casualmente os acontecimentos sociais, os comportamentos, as instituições ou os processo; ela é um contexto, algo dentro do qual eles podem ser descritos de forma inteligível - isto é, descritos com densidade. (GEERTZ, 1973, p. 24).

Uno de los ejes para pensar la cultura es la existencia de la lengua y la formación del binomio lengua/cultura como estructura quasi inseparable que media todas nuestras experiencias sociales. El contacto, el aprendizaje y la enseñanza de una lengua implican, entonces, adentrarse en la cultura de la que forma parte. Siguiendo a Mariza Riva de Almeida (2011), Reinaldo Fleuri (2003) y Marcos Dos Reis Batista (2008), esta definición implica considerar que el conocimiento de la cultura es parte inherente a la competencia comunicativa, ya que ésta va más allá del manejo de la lengua y permite, al mismo tiempo, la interculturalidad. En la misma línea, Miquel (1999) sostiene que en la enseñanza de lenguas extranjeras es necesario trabajar con la competencia cultural, dado que la cultura junto con la 
lengua actúan como filtros para actuar, pensar, organizar e interpretar el mundo. Así, resulta imprescindible tener en cuenta que en el acto de comunicación hay elementos ajenos a la competencia lingüística y que pertenecen a la adecuación pragmática.

La interdependencia entre lengua y cultura está dada en tanto la lengua no sólo supone un sistema de sonidos, sintaxis y vocabulario, sino que forma parte de los procesos socio-culturales. Como sabemos, la competencia comunicativa implica relacionar la actividad lingüística con algunos aspectos de la comunidad hablante, al menos en tres campos: las referencias culturales, las rutinas y usos convencionales, y las convenciones sociales y comportamientos no verbales (lenguaje del cuerpo y gestualidades), lenguaje-objeto, como artefactos, vestuarios, adornos, etc. y lenguaje-ambiente, compuesto de las características del espacio, la arquitectura, entre otros (Dos Reis Batista, 2008). En este sentido, el aprendizaje de una lengua está siempre asociado a un contexto amplio, más allá de la gramática formal. Por ello, no parece suficiente aprender sólo reglas y formas lingüísticas.

Existen maneras de expresar y modalidades culturales de estructurar el habla que es preciso conocer, puesto que no se habla cualquier cosa donde y cuando se desea. Esto se vincula con que, como sostiene Bourdieu (1983), la lengua y todas las prácticas sociales y culturales están producidas por agentes sociales que se encuentran inmersos en contextos relacionales. La lengua es una praxis, fundamentalmente, porque no ocurre en el vacío, sino que está construida socialmente y adecuada al contexto, la situación, los interlocutores que tenemos enfrente, etc. ${ }^{1}$ Esto implica la existencia de ciertas estructuras sociales más o menos estables -aunque pasibles de ser modificadas- que condicionan y atraviesan las acciones sociales. La lengua, como las prácticas sociales, significantes y con un sentido, es puesta en juego en la relación con otros.

Esta perspectiva resulta productiva en el proceso de enseñanza-aprendizaje de una lengua extranjera para descentrar la mirada hacia una cultura diferente de la nuestra y considerar el posible encuentro entre culturas como un cruce -no sin tensiones- entre estructuras que pertenecen a procesos sociales diversos pero que pueden entrar en comunicación e intercambio. En este sentido, hemos destacado la importancia de establecer la relación que hemos llamado "binomio lenguacultura" en las clases sobre temas vinculados con la cultura en la enseñanza de

\footnotetext{
1 Según Bourdieu (1983) en el campo de los intercambios lingüísticos es necesario reconocer, además, la existencia de una lengua legítima que entra en una relación de fuerza simbólica con otras lenguas no autorizadas. Utilizarla de un modo adecuado implica obtener un valor social o distintivo.
} 
lenguas extranjeras. ${ }^{2}$ Es posible, sin embargo, adentrarnos más profundamente en las modalidades de encuentro entre la propia lengua-cultura y la extranjera.

\section{INTERCULTURALIDAD, LENGUA Y EDUCACIÓN}

Una vez establecido el punto de partida que es la relación entre lengua y cultura, proponemos avanzar hacia una mirada que, además de tener en cuenta estos rasgos -especialmente para las clases de lengua extranjera- considere la incorporación de contenidos específicos para los futuros profesores, más allá de las clases de lengua.

En la práctica de la enseñanza de una lengua extranjera se juega ${ }^{3}$, entonces, el posible encuentro e interacción entre dos culturas diferentes, la interculturalidad. ¿Qué es la interculturalidad y cuál es su significado e importancia en el proceso educativo? La interculturalidad se basa en la necesidad de comprender lo diferente de cada cultura y asumir la posibilidad de la convivencia democrática en tanto el "otro" representa una alteridad no asimilable, ni unificable, sino inmersa en su propia condición histórica como sujeto de enunciación. De esta manera, la interculturalidad implica, por un lado, la convivencia democrática entre grupos y culturas nacionales, el reconocimiento de las diferencias y la paridad de derechos, el respeto a las diferencias y su integración sin anularlas (FLEURI, 2003) y, por último, la necesidad de salir del etnocentrismo. Según Dos Reis Batista,

ao ensinar língua-cultura, tem-se a necessidade de desenvolvermos por meio da interação entre pessoas de diferentes culturas uma relação baseada no respeito às diferenças, desenvolver ou despertar a consciência que o outro não é melhor ou pior, apenas diferente. Não se trata do aprendente abandonar a sua cultura para absorver a outra e, sim, criar uma ponte de reflexão e aprendizagem da cultura estrangeira, respeitando a sua própria cultura também. Esse processo de interação faz parte do processo chamado interculturalidade (2008, p. 2).

Este concepto difiere de las posturas etnocéntricas donde se utiliza la propia cultura como medida para valorar y/o subestimar las demás culturas, en tanto se impone el punto de vista, los valores, la forma de vida y la lengua propia como únicos legítimos, lo que conlleva una desvalorización de lo diferente. Aquí, junto

2 Nos referimos a los trabajos presentados en el VII Encuentro Académico del Departamento de Lenguas y Literaturas Modernas.

3 Además de la enseñanza de lenguas extranjeras, este encuentro puede producirse en diversas circunstancias, como la inmigración, los viajes de estudios, de trabajo y de placer y el amplísimo uso de las redes sociales que facilitan la comunicación entre puntos distantes del globo. 
con la cultura, vemos la importancia que tiene la lengua en el encuentro entre culturas. En nuestra región, como se sabe, esto ha sido especialmente llevado a cabo desde una mirada eurocéntrica, a partir de la cual la cultura europea se presentaba como el modelo natural y racional a seguir (FLEURI, 2003). Esto permitía justificar la colonización, el ejercicio de la violencia y la imposición de los cánones culturales y lingüísticos del país conquistador, en tanto se suponía que el pueblo conquistado carecía de la racionalidad y civilización que guiaba el pensamiento y la vida de los conquistadores. Así, los pueblos americanos eran concebidos -también por las propias elites localescomo menos evolucionados, incivilizados e inferiores, principalmente desde la teoría evolucionista. Todo ello se veía claramente en el desprecio que en general se tuvo hacia los indígenas y negros que habitaban estas tierras.

La interculturalidad, tal como la entendemos, también se distingue de la idea de asimilación de una cultura en otra, proceso por el que -en general, a partir de la inmigración- se pierden los rasgos y lenguas propios para tomar la cultura anfitriona y abandonar la de origen. Del mismo modo, tampoco significa la bomogeneización de diversas etnias en una única identificación posible, tanto en lo lingüístico como en lo cultural.

Así, la interculturalidad debería ser entendida como un proceso permanente de relación, comunicación y aprendizaje entre personas, grupos y conocimientos. En un sentido similar, Homi Bhabha acuñó el concepto de "diferencia cultural" (2002), que alude a un cambio de posición en el proceso de enunciación de la cultura, es decir, un proceso de significación en el que las culturas no aparecen como cristalizaciones esencializadas, sino que se centra en los momentos que producen una articulación de las diferentes culturas, los "entre-medio". Así, Bhabha afirma que

La cuestión de la diferencia cultural nos enfrenta con una disposición de conocimientos o una distribución de las prácticas que existen una junto a otra, abseits que designan una forma de la contradicción o el antagonismo social que tienen que ser negociadas más que negadas superadoramente (BHABHA, 2002, p. 198).

Esta idea implica tener en cuenta la complejidad y los posibles conflictos que se dan en procesos de enunciación de una cultura al articularse con otra. Los espacios "entre-medio" son cruciales porque en ellos no existe la asimilación ni la homogeneización, especialmente en el caso que le interesa a Bhabha, el de las minorías culturales. Para esclarecer más este concepto, el autor sostiene que

Estos espacios 'entre-medio' [in-between] proveen el terreno para elaborar estrategias de identidad [selfhood] (singular o comunitaria) que inician nuevos signos de identidad, y sitios innovadores de colaboración y cuestionamiento, en el acto de definir la idea misma de sociedad. 
Es en la emergencia de los intersticios (el solapamiento y el desplazamiento de los dominios de la diferencia) donde se negocian las experiencias intersubjetivas y colectivas de nacionalidad [nationness], interés comunitario o valor cultural (BHABHA, 2002, p. 18).

La importancia de los conceptos de diferencia cultural y de "entre-medio" radica, en parte, en que las culturas no preexisten como objeto fijo de conocimiento, sino que se construyen discursivamente, es decir que en el propio momento de enunciación se niega la certidumbre y la estabilidad de la cultura, así como limita los estereotipos culturales y raciales.

La perspectiva hasta aquí planteada tiene un valor fundamental en la enseñanza de lenguas extranjeras. Como señala García Benito (2009), la interculturalidad no significa solo que el profesor de lenguas extranjeras enseñe contenidos de la cultura de la lengua objetivo, sino que él mismo tiene que implicarse en el cambio de actitud para incentivar una forma de pensamiento intercultural.

En este sentido,

además de construirse a partir de una declaración de principios, [la interculturalidad] debe traducirse en una propuesta didáctica, aunque no se limite a ella, que pueda ponerse de manifiesto a través de la presentación de consignas diversas que recuperen diferentes actitudes de valoración por los saberes de las comunidades, que presente los contenidos como formas de interpretación de la realidad y la historia, no como saberes cerrados, que favorezca el intercambio de ideas y opiniones (DIEZ, 2004, p. 204).

Es decir, el tratamiento de la interculturalidad en el campo de la educación debe ser un marco presente en la práctica educativa (en el ámbito pedagógico, la formación-capacitación docente y el desarrollo de materiales didácticos), más aún si nos referimos a la enseñanza- aprendizaje de una lengua extranjera.

En síntesis, el trabajo sobre el binomio lengua/cultura y la interculturalidad para la enseñanza-aprendizaje de una lengua extranjera, supone, además, la necesidad de generar estrategias y propuestas didácticas adecuadas para ser implementadas en el contexto áulico. A continuación desarrollaremos con mayor profundidad esta cuestión.

\section{ALGUNAS CONTRIBUCIONES PARA PENSAR LA CULTURA EN EL CASO DEL PORTUGUÉS COMO LENGUA EXTRANJERA}

En este apartado, desarrollaremos una descripción del trabajo que se viene realizando en la cátedra "Cultura y Sociedad", asignatura de modalidad cuatrimestral, que se inserta en el bloque de materias del Ciclo de formación 
cultural y corresponde al primer año de la carrera del Profesorado en Portugués de la Universidad Nacional de La Plata. Esta materia realiza un aporte específico al amplio marco teórico que se les brinda a los futuros profesores para que obtengan una completa formación que no sólo sea de excelencia en el plano de la lengua, sino que también abarque otras áreas de conocimiento vinculadas a la sociología, los estudios culturales, literarios y artísticos, así como a la historia del mundo lusobrasileño con una impronta intercultural.

Al observar el programa general de la materia, podremos notar que cada uno de los temas y unidades da cuenta de los principales conceptos y teorías relacionados con la cultura, la lengua, la identidad, el poder y el arte, en suma con la sociedad y su constante vinculación con las características específicas de Brasil. De esta manera, se incluye bibliografía de autores clásicos, así como otros textos explicativos y diseñados para introducir las principales problemáticas sobre los mismos y brindar un panorama general. En efecto, y según la experiencia en la cátedra, la articulación de conceptos y teorías con análisis de casos y la experiencia vivida en la propia cultura y en la extranjera, así como los aportes de los alumnos argentinos y brasileños, resultan enriquecedores y productivos a la hora de aprehender los contenidos propuestos. Es por ello que enfatizamos la necesidad de pensar de forma articulada la lengua y la cultura en el proceso de enseñanzaaprendizaje del portugués como lengua extranjera.

A grandes rasgos, entre los objetivos planteados por la cátedra, se considera sustancial orientar al estudiantado para la comprensión de los caracteres de la cultura y la sociedad como resultados de procesos humanos en permanente cambio e históricamente construidos y, en estos términos, también contribuir a identificar los aspectos que hacen de la lengua parte fundamental de la cultura y la importancia del binomio que forman (lengua/cultura) en el proceso de enseñanza-aprendizaje del portugués como lengua extranjera. Asimismo, a lo largo del dictado de la materia, se propone por un lado reflexionar sobre la propia mirada respecto del "otro" y las modalidades de vincularnos con la diversidad social y cultural, así como sobre los estereotipos y clasificaciones propios del sentido común, y por otro relacionar, diferenciar y encontrar raíces comunes entre la experiencia vivida en la propia cultura y la extranjera y poder actuar en las tensiones y conflictos entre ambas, considerando también el enriquecimiento resultante del proceso intercultural.

Teniendo en cuenta la idea de que la comprensión de cuestiones vinculadas con la cultura y la sociedad son necesarias para los futuros profesores de lenguas extranjeras, los temas a indagar a lo largo de la materia se enlazan con una conceptualización de la cultura como un conjunto de prácticas compartidas, 
"comunes" u "ordinarias" (WILLIAMS, 2007) y que tejen "tramas de significaciones" en un grupo o sociedad determinadas (GEERTZ, 1973). Esto significa adscribir a una noción amplia de cultura, que incluye tanto el comportamiento aprendido, como la forma de organización de las familias, las instituciones y la comunicación, que establece ciertas pautas y rige las relaciones sociales. Como puede verse, este concepto se diferencia de una idea elitista de "alta cultura" y trata, por el contrario, de lo que produce una sociedad incluyendo a las clases populares. A partir de allí, es posible pensar cómo la cultura se practica y se elabora, es decir, lo que se hace en términos culturales en una sociedad determinada, lo que se reproduce pero también lo que se produce como novedoso o emergente. Al mismo tiempo, y en consonancia con la perspectiva general de los estudios culturales, la vinculación de estas prácticas culturales con las relaciones de poder subyace a muchas de las afirmaciones aquí presentadas. Además, una decisión fundamental para esta materia es el abordaje de la relación entre cultura y sociedad no como una relación de exterioridad, sino en la dialéctica que implica pensar la cultura en el contexto social y político del que forma parte.

En concordancia con lo anterior, se propone una mirada crítica sobre el orden social, es decir, que entienda las desigualdades, injusticias y sometimientos como problemas a conocer, analizar y desentrañar. Esta tendencia que tuvo su origen en interpretaciones del mundo como conflicto, especialmente en su versión marxista, es tomada en la asignatura "Cultura y sociedad" en términos menos definitivos, pero constituye una base común para plantear los temas y autores del programa. Esta visión del conflicto social no invalida tener presente a la hegemonía que, en términos gramscianos, permite pensar el acuerdo y el consenso entre las clases, y especialmente a la cultura como uno de los lugares claves donde se desarrolla la lucha por dicha hegemonía.

Teniendo en cuenta esta orientación dada a la materia y la particularidad del profesorado al que pertenece, se considera que la figura del "otro" es un elemento clave para la comprensión de muchos de los temas. En este sentido, se lo concibe como una entidad diferente del "yo", tanto en términos de género, etnia, clase social o cultura. Así, es necesario posicionarnos crítica y reflexivamente en dos sentidos: pensar el "otro" respecto de "nosotros", y también nosotros en tanto "otro" respecto al europeo o norteamericano, es decir, en relación con la cultura dominante occidental. El trabajo sobre esta representación del "otro" permite abrir una disposición al pensamiento que evite la estigmatización de lo diferente como lo opuesto, oscuro o indeseable. Esta es la clave de lectura que influirá a la hora de establecer una mirada intercultural en la enseñanza de una lengua extranjera, 
en tanto se sostenga una idea de interculturalidad que no elimine las diferencias ni apele a una asimilación, sino que, contrariamente a las posiciones homogeneizadoras o normalizadoras, construya relaciones a partir del establecimiento de dicha diferencia, en función del cual es posible "negociar" o "traducir". La posibilidad de abrirse al extrañamiento y la deslocalización de lo desconocido permite, entonces, vivir y pensar nuestros patrones culturales en el marco de un conjunto de patrones diferentes, según cada sociedad o grupo social. En este sentido, esta perspectiva reconoce la importancia de comprender los sentidos de las prácticas culturales en el marco de la historia, las ideas imperantes, los procesos sociales y económicos locales.

Para llevar a cabo estas elecciones, en el armado del programa de "Cultura y sociedad" se operativizan los temas tratados en cada unidad en casos concretos, históricos, sociales y culturales. De este modo, se particularizan en función de la cultura y la sociedad brasileña, en concordancia con la orientación dada al profesorado. Con respecto a esto, es importante aclarar que en las sucesivas materias del Ciclo de formación cultural de la carrera se tratarán en profundidad temas de la historia, las ideas, las relaciones internacionales, entre otros, que aquí sólo se introducen para especificar y pasar a casos concretos las teorías y conceptos estudiados. En esa tesitura, se plantean relaciones con la cultura y la sociedad brasileñas, tales como: el vínculo entre lengua y cultura específicamente en la enseñanza del portugués, el capital cultural, el poder simbólico y la legitimidad en el consumo de música en Brasil, los cambios sociales producidos en el género y las familias brasileñas, las identidades de negros e indígenas en Brasil, la ruralidad y los movimientos brasileños de lucha por la tierra, los cambios en la religiosidad en Brasil, el desarrollo del racismo, la esclavitud y las estrategias de resistencia al sometimiento en ese país, las manifestaciones artísticas brasileñas relacionadas con momentos de cambios sociales y culturales.

La estrategia para efectuar este anclaje implica no sólo el uso de bibliografía brasileña que versa sobre estos temas, sino también la visualización de videos en lengua portuguesa, la mayoría de ellos producidos en Brasil, así como la utilización de fuentes escritas y recursos visuales provenientes de ese país. Estas herramientas se utilizan tanto en clases "teóricas" como "prácticas", sin embargo, la mirada particular sobre casos brasileños se ha privilegiado en las clases "prácticas", en tanto se considera que es posible guiar primero los contenidos teóricos generales y luego establecer un estudio más específico y concreto para el caso brasileño. 


\section{PROPUESTA METODOLÓGICA Y TRABAJO EN EL AULA}

En relación con las estrategias de enseñanza-aprendizaje, el objetivo principal de la asignatura "Cultura y sociedad" excede el "dar clase" y es guiar el aprendizaje de los alumnos. Esto implica, en primer lugar, presentar la información, supervisar la decodificación que de ella realicen los alumnos y la forma en que la integran a saberes previos, ofrecer actividades y experiencias guiadas y, finalmente, establecer el proceso evaluativo.

El sistema de trabajo en el aula tiene una dinámica expositiva y participativa, en la que se parte de los conocimientos previos de los alumnos, seguido del diálogo sobre los mismos y la exposición del docente, proceso que se va combinando con las intervenciones de los estudiantes en todo el trayecto. Se busca tanto el aprendizaje de los contenidos de cada unidad a través de la lectura previa por parte de los alumnos de la bibliografía indicada para cada clase, como por la fase expositiva de las docentes y la interacción lograda en el aula entre todos los miembros. De allí que tiene también un carácter participativo, donde los alumnos pueden aportar sus conocimientos previos, posibles hipótesis de lectura e información, así como dudas y cuestionamientos.

Por otro lado, se construyen nexos entre autores y teorías, así como entre conceptos y experiencias históricas, sociales, culturales, evitando la totalización o esencialización de los conceptos y estableciendo siempre una vinculación directa con los casos empíricos. Esto facilita tanto la comprensión de los conceptos y teorías, como el anclaje y el análisis crítico de fenómenos sociales y culturales.

Se trabaja con guías de preguntas que ayudan a localizar los puntos críticos y nodales de cada tema, así como a establecer relaciones entre autores o textos, puntos de contacto y diferencias. También se realizan trabajos sobre los textos teniendo siempre en cuenta la lengua extranjera en que están escritos y las dificultades que esto acarrea.

Asimismo, la experiencia con que cuentan los alumnos, tanto en el aprendizaje de la lengua extranjera, como en los casos en que hayan tenido práctica docente previa (situación frecuente) es de fundamental importancia como aporte a la construcción del conocimiento. En los casos en que hayan tenido contacto con otros países, especialmente Brasil y el mundo luso, sus contribuciones para reflexionar sobre los temas de la asignatura son relevantes y estimulantes. Asimismo, se tiene especialmente en cuenta la procedencia, dada la frecuencia de alumnos brasileños entre los inscriptos en esta materia. Su presencia en el aula es fructífera en tanto han realizado aportes desde sus experiencias vividas, sus conocimientos acerca de la cultura y sociedad brasileña y sus modos de vida, todo lo cual ha significado un 
complemento para el desarrollo de las clases, al mismo tiempo que ha resultado provechoso a partir del diálogo con sus pares en la situación áulica.

El cómo enseñamos es el escollo en que la didáctica se pone en juego, por lo que resulta necesario conocer los saberes y experiencias previos de los estudiantes y sus mecanismos de aprendizaje. Esto obtiene relevancia al momento de pensar en la compleja relación que se establece entre la teoría y la práctica, acudir a las transposiciones didácticas que facilitan la transformación del objeto de saber en objeto de enseñanza. De ello se desprende el contrato didáctico-pedagógico que generará un proyecto de enseñanza y aprendizaje compartido entre los docentes y los alumnos cuyo objeto es el saber en el hacer áulico.

Otra particularidad del dictado de esta materia es que se utilizan en todas las clases medios o recursos, tales como imágenes, videos, entrevistas, notas periodísticas y otras fuentes históricas que permitan objetivar los conocimientos que se pretenden alcanzar y que funcionen como estrategias que fomenten la interpretación y reflexión crítica. Se trata de recursos producidos en portugués, ya que permiten un mayor acercamiento a la lengua $y$, en general, a los temas tratados en cada unidad. El uso de los recursos audiovisuales se fundamenta, además, en que funcionan como disparadores en algunos casos, como afianzadores del conocimiento en otros casos, y siempre como herramienta crítica que permite la reflexión y el debate acerca de lo visto. Estas situaciones, frecuentes en cada clase teórica y práctica, fueron, por lo que hemos podido evaluar, valoradas muy positivamente por los alumnos, quienes destacaron la utilidad de las mismas y el dinamismo que agregaron a las clases.

Finalmente, el uso de estas herramientas se fundamenta en una adecuación de la docencia a las prácticas socio-culturales actuales, donde el empleo de sistemas y redes de comunicación por computadoras está casi generalizado, logrando, de este modo, un aggiornamento que vincule la experiencia cultural actual de amplios sectores de la sociedad, y en especial en la enseñanza superior, con los procesos de enseñanza-aprendizaje de la cátedra.

Las clases de "Cultura y sociedad" son dictadas en español, sin embargo se utilizan bibliografía y recursos en portugués. Dado que algunos alumnos ingresantes pueden tener dificultades con el acceso a la lengua, se realizan encuentros con los profesores de taller de portugués y de lengua portuguesa para resolver dudas y fortalecer el acercamiento al lenguaje técnico de las Ciencias Sociales existente en los textos, videos y otras fuentes utilizadas. Con el mismo objetivo, se promueve la discusión en clase sobre las dificultades que aparezcan respecto a estos temas y su resolución entre pares. 
En resumen, la metodología propuesta en la materia consiste en tres grandes aspectos. En primer lugar, partir de los conocimientos y nociones previos de los alumnos, considerando asimismo las motivaciones y los intereses propios de los sujetos que aprenden en los procesos de enseñanza. Esto no supone que aprendan a partir solamente de "su universo de conocimientos" (ya que toda motivación o interés siempre surge a partir de lo que se conoce) sino que el docente debe ampliarles dicho universo para que sus motivaciones sean mayores. En segundo término, privilegiar el uso de materiales didácticos en lengua portuguesa, posibilitando la interacción entre docentes y alumnos. Con respecto a esto, identificamos dos ventajas. Por un lado, el uso de soportes visuales y audiovisuales en los procesos educativos, acompañando a los textuales, a la vez que dinamiza la clase, resulta motivador y estimula el interés de los estudiantes. Por otro lado, dichos recursos, que acercamos a los estudiantes en portugués, significan un aporte sustancial para la enseñanza - aprendizaje en tanto dan cuenta de la lengua como parte fundamental de la cultura. En tercer lugar, en las clases se valora la experiencia personal de los estudiantes tanto argentinos como brasileños, favoreciendo el intercambio y el diálogo entre ellos.

A continuación desarrollaremos brevemente cuatro ejemplos en base a diferentes temas abordados en la materia "Cultura y sociedad" que ponen en evidencia el modo de abordaje de la metodología propuesta para incluir temas de cultura en la enseñanza-aprendizaje de una lengua extranjera.

Ejemplo 1- Unidad: Identidad. Tema: racismo

En el caso de los futuros profesores de portugués resulta especialmente importante para abordar la cuestión de la identidad el análisis situado en Brasil: las relaciones étnicas y las bases raciales de la identificación de negros e indios, lo cual implica también el estudio de la anulación, descalificación y des-subjetivación que operaron con fuerza en el pasado brasileño y resuenan en la actualidad (DA MATTA, 1984; GUIMARÃES, 2004). Para ello, se estudian también el origen de las teorías raciales en Brasil y los cambios que se han producido a través del tiempo, haciendo hincapié en la noción de "democracia racial" (ORTIZ, 2006; RIBEIRO, 1995). Asimismo, para conocer brevemente una de las políticas llevadas a cabo en ese país para la inclusión de diferentes grupos étnicos se analiza el "Questionário básico, Censo Demográfico 2010", producido por el Instituto Brasileiro de Geografia y Estatística, donde se aborda específicamente el tratamiento que se hace del tema a través de las preguntas del cuestionario, tales como: "A sua cor ou raça", "Etnia ou o povo a que pertence", "Fala língua indígena no domicílio", entre otras (Imagen 1). 
En este caso, resulta productivo elaborar reflexiones sobre las estrategias estatales de registro de la diversidad al interior de la población, asimismo, analizar los significantes utilizados en el censo para referir a dicha diversidad.

Además de la propuesta de las docentes, resulta interesante destacar que los alumnos aportaron notas periodísticas sobre casos de racismo actual en Brasil (imagen 2). Sobre el artículo "A política que barra negros e pobres e ameaça a democracia da areia no Rio" (MARTÍN, 2015), se realizó una lectura colectiva en el aula y se analizó su contenido, teniendo en cuenta tanto el tipo de mirada presentada por el periódico, como su relación con la perspectiva ofrecida por la cátedra.

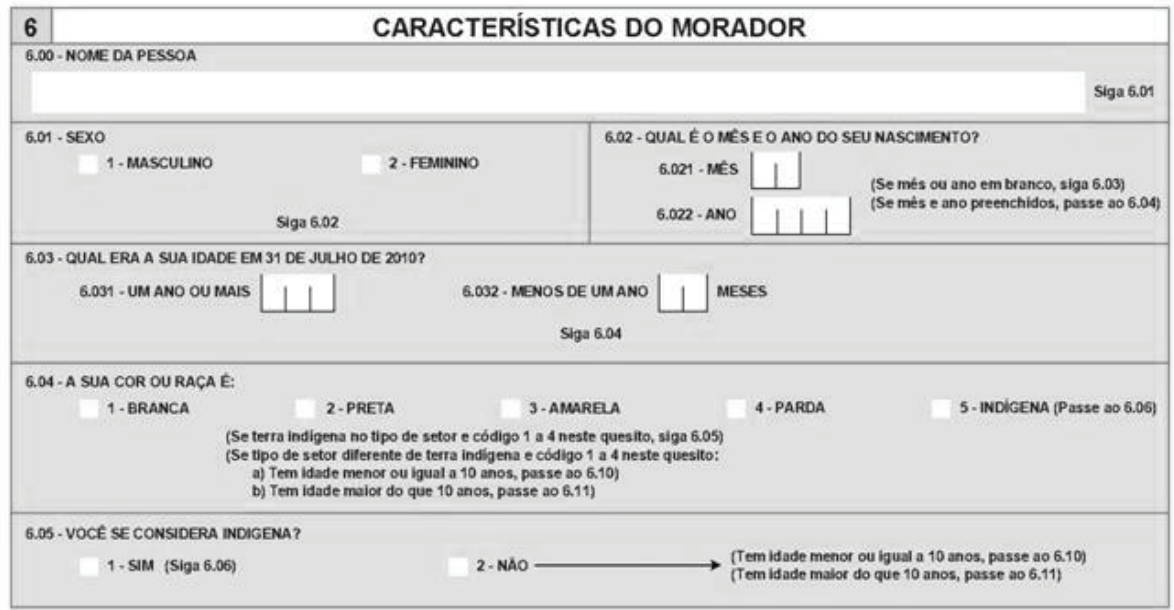

\begin{tabular}{|c|c|c|}
\hline \multicolumn{3}{|c|}{606 - QUAL E A SUA ETNLA OU O POVO A QUE PERTENCE? } \\
\hline \multicolumn{3}{|c|}{ 6.07 - FALA LiNGUA INDIGENA NO DOMCiUL? (Considere também o uso da lingua de sinals) } \\
\hline 1. SIM (Siga 6.08) & 2-NAO (Passe ao 6.09) & \\
\hline \multicolumn{3}{|c|}{$\begin{array}{l}608 \text { - QUAL(IS)? } \\
\text { (ESPECIFIOUE A(S) LINGUA(S) INDIGENA(S) - ATE DOIS REGISTROS) }\end{array}$} \\
\hline \multicolumn{3}{|l|}{6.081} \\
\hline \multicolumn{3}{|l|}{6083} \\
\hline \multicolumn{3}{|c|}{ 6.09 - FALA PORTUGUES NO DOMECiUO? (Considere também o uso da lingua de sinais) } \\
\hline 1. $\sin$ & 2-NÄO & $\begin{array}{l}\text { (Tem idade menor ou igual a } 10 \text { anos, siga } 6.10 \text { ) } \\
\text { (Tem idade malor do que } 10 \text { anos, passe ao } 6.11 \text { ) }\end{array}$ \\
\hline
\end{tabular}

\section{Imagen 1}

Questionário básico (recorte), Censo Demográfico 2010, Instituto Brasileiro de Geografia y Estatística 
29/3/2016

A pol|fica que barra negros e pobres e ameaça a democracia da areia no Rio | Internacional | EL PAIS Brasil

\section{INTERNACIONAL}

AVANCE Consulta la primera página de EL PAÍS, Edición América, del martes 29 de marzo de 2016 »

VIOLÊNCIA POLICIAL ,

\section{A política que barra negros e pobres e ameaça a democracia da areia no Rio}

Polícia prende jovens antes da chegada às praias, mas juiz diz que prática é ilegal

\section{MARIA MARTÍN}

São Paulo - 31 AGO 2015 - 15:56 ART

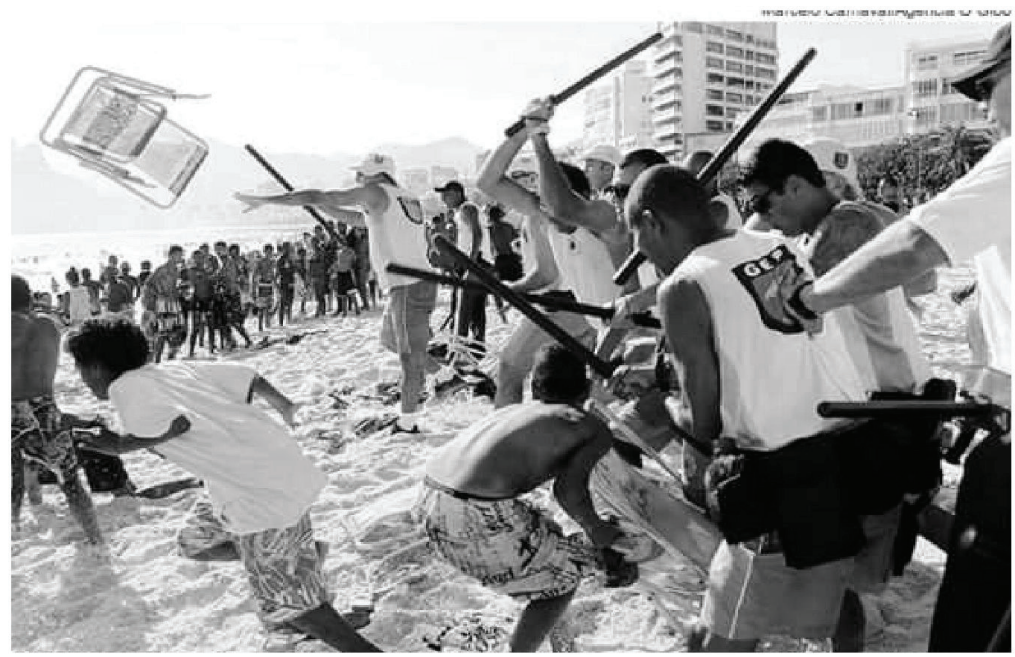

Os rapazes, negros e pobres, viajavam em vários ônibus de linha regular até a privilegiada zona sul carioca. $O$ destino, no domingo passado, eram as praias mais famosas do mundo, mas eles acabaram no fundo de um furgão policial, sem ter cometido nenhum crime. A ação pretendia conter uma nova

Imagen 2

"A política que barra negros e pobres e ameaça a democracia da areia no Rio", El País, 31 agosto de 2015 
Ejemplo 2- Unidad: Identidad. Tema: religiosidades en Brasil

Por otro lado, trabajar con las identificaciones y prácticas religiosas, sus mutaciones a lo largo de las últimas décadas, basadas en la diversidad de creencias y prácticas tanto tradicionales (el catolicismo), como de raíz africana y sus derivaciones y mixturas, es otra de las formas de concebir la identidad. Se aborda particularmente desde el eje de los cambios producidos en Brasil respecto de las prácticas religiosas, específicamente el fenómeno del tránsito religioso que se observa en la pérdida de creyentes católicos, el aumento de los pentecostales y el crecimiento de una franja de no creyentes (ALMEIDA Y MONTEIRO, 2001; PIERUCCI, 2004; NASCIMENTO, 2010). Estos procesos se analizan en el marco de los cambios sociales y culturales de Brasil. Los videos "Especial Novembro Negro - Religiões de matriz africana: unidade e diversidade" y "Especial: A intolerância contra as religiões de matrizes africanas no Brasil" abren el debate, permiten trabajar sobre los prejuicios y ofrecen datos e imágenes sobre el tema ${ }^{4}$ (Imagen 3).

De acuerdo con la perspectiva de la cátedra, más que desarrollar las características de las religiosidades en Brasil en abstracto, resulta productivo tener presente los cambios sociales y culturales en relación con dichas prácticas. En particular, una alumna, relacionando el tema de racismo con el de religión, aportó a la clase un caso de discriminación hacia una niña brasilera, negra, practicante de la religión umbanda. De esta manera, además de relacionar los diferentes temas que se van viendo en clase, se dialogó sobre temas actuales de Brasil y el problema de la discriminación racial y la intolerancia hacia otro tipo de prácticas religiosas no hegemónicas.

4 Videos como estos, que muestran filmaciones de prácticas religiosas de origen africano permiten, además de conocer y reflexionar sobre el tema, en muchos casos, permiten visualizar por primera vez este tipo de actividades. Así sucedió en 2015, donde las alumnas desconocían los modos en que estas prácticas y rituales se llevaban a cabo, aún quienes provenían de Brasil. 


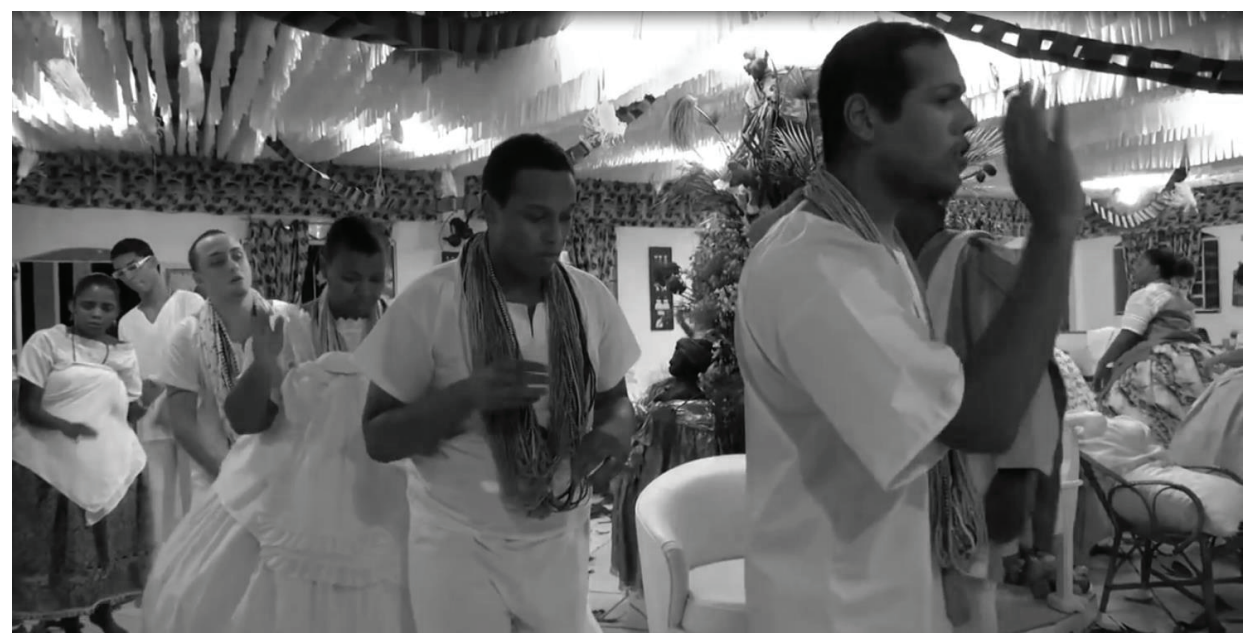

Imagen 3

Imagen del video "Especial: A intolerância contra as religiões de matrizes africanas no Brasil", ONU Nações Unidas no Brasil

Ejemplo 3- Unidad: poder. Tema: microfísica del poder

Uno de los temas estudiados en "Cultura y sociedad" es el poder y, para ello, es central pensarlo como relación, a partir de la teoría de Michel Foucault (1984, 1987, 1995). Con ese fin, se introducen los principales conceptos de su teoría, especialmente los tres procesos paralelos que describe el autor: el desplazamiento de los estilos punitivos, el surgimiento de un complejo jurídico-político con sus dispositivos de saber-poder y el desarrollo de dos macroprocesos: la economía capitalista y el estado moderno. En función de esto, se analiza la teoría del autor sobre la sociedad disciplinaria, en estrecha vinculación con su concepto del poder como una red y sin un centro único. La microfísica del poder y la tecnología política del cuerpo son elementos fundamentales para analizar el ejercicio del poder, del que depende la obtención de cuerpos útiles para la economía y dóciles en la política. Acorde a la perspectiva planteada al comienzo del artículo, es clave realizar una referencia y una reflexión sobre la actualidad de los problemas vinculados con el poder, el racismo, los elementos que aún subyacen en la mirada hacia los negros y el lugar que ocupan en la sociedad actual brasileña. Además, es relevante vincular los problemas étnicos y de color con la clase social, así como la función del estado y los empresarios en la organización de la nación brasileña (RIBEIRO, 1995). 
En función de esta mirada, se promueve un trabajo práctico sobre diversas imágenes de historietas y fotografías referidas al ejercicio concreto del poder y la sociedad disciplinaria (imagen 4). Allí, imágenes sobre el trabajo, el sometimiento, el lugar de la mujer y la disciplina en la escuela, permiten establecer una reflexión y un diálogo sobre estos temas en la actualidad tanto brasileña como en general. De esta manera, en la clase se vincularon dichas imágenes y situaciones con los conceptos teóricos centrales (poder -que transita transversalmente, de forma reticular-, sociedad disciplinaria y cuerpo), lo cual se enlaza no sólo con procesos históricos pasados (como la esclavitud en Brasil) sino con situaciones vividas diariamente. Asimismo, esto permitió el relato de experiencias propias relacionadas con el tema de la clase.

\section{Imágenes de historietas y fotografía para el trabajo práctico sobre el poder y la sociedad disciplinaria.}
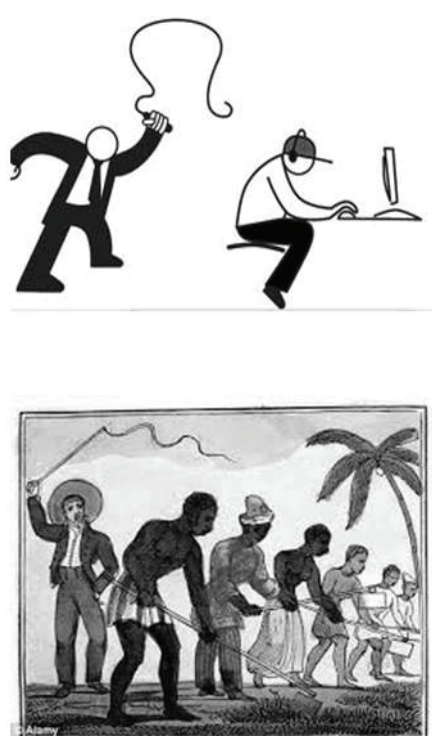
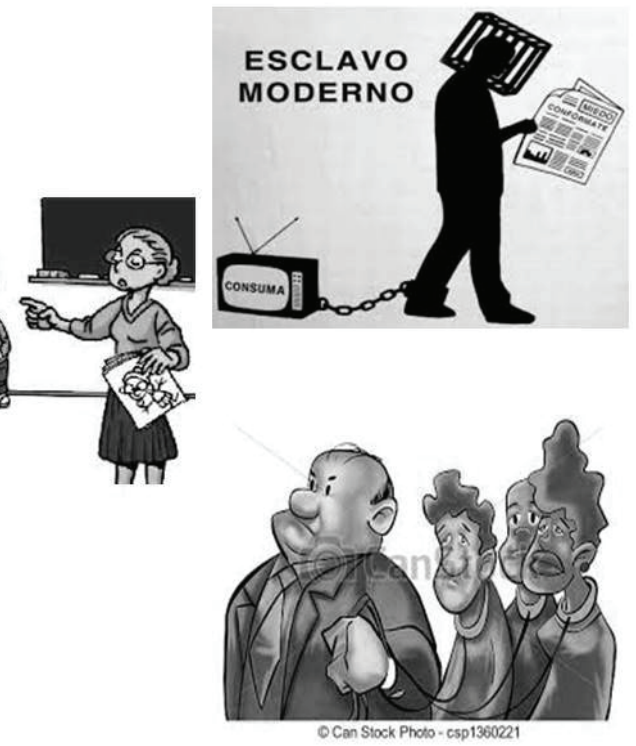

\section{Imagen 4}

Elaboración propia en base a imágenes de dominio público.

Ejemplo 4- Unidad: Arte. Tema: Vanguardias del siglo XX y la construcción de la identidad nacional 
Como parte del estudio de la cultura, en "Cultura y sociedad" se estudian algunas prácticas de las artes visuales que permiten pensar al arte -siguiendo a Williams (2003) - como parte del conjunto del proceso social y, por lo tanto, con capacidad para dar cuenta de él. Sin embargo, la especificidad de las prácticas artísticas hace que no funcionen como "reflejo", sino como producciones sociales expresivas y potentes para generar experiencia y hasta nuevas miradas sobre el mundo. Esto implica, además, pensarlo dentro de la cultura más allá de sus aspectos técnicos, sino en su red de significados, como un sistema cultural (GEERTZ, 1973).

Para la comprensión de algunos fenómenos culturales en el caso brasileño, se ha recurrido a dos movimientos históricos relevantes: el modernismo de las primeras décadas del siglo XX y las vanguardias de los años '60 y '70 como claves para entender la cultura, las relaciones de poder y los cambios sociales. Con respecto al primero, el modernismo y algunas de sus figuras más destacadas resultan productivos para posicionar la mirada sobre la relación colonia/metrópoli, colonizador/colonizado y la invención de un proyecto de identificación nacional. En las clases se analizan dos manifiestos clave para comprender este proceso: "Manifesto da Poesia Pau - Brasil" (ANDRADE, 1924) y "Manifesto Antropófago" (ANDRADE, 1928).

Se analiza en clase el caso del proyecto Pau Brasil (1922), que, en el contexto del modernismo brasileño e influenciado por el nacionalismo de la época, pone en discusión la diferencia entre la lengua portuguesa y el lenguaje practicado por los brasileros. De esta forma, la poesía nacional posterior a Pau Brasil recupera elementos diferenciadores: modismos populares, lenguaje cotidiano, otra gramática-que antes estaban vedados (BOAVENTURA, 1986). Durante el desarrollo de la clase, los alumnos aportaron poemas inscriptos en esta corriente y comparaciones con el caso de la vanguardia argentina, contenidos vistos en otras materias del profesorado.

Asimismo, una alumna brasileña aportó un poema de Oswald de Andrade -referente del proyecto Pau Brasil- que recitó espontáneamente durante la clase en que se trabajaba sobre el tema y constituyó un material relevante para trabajar en el aula con el resto de los estudiantes. La alumna, junto con sus compañeros, realizaron un análisis del poema, sus implicancias y su relación con Pau Brasil, especialmente en torno a la construcción de la identidad brasileña y su relación con la lengua. 
Pronominais

Dê-me um cigarro

Diz a gramática

Do professor e do aluno

E do mulato sabido

Mas o bom negro e o bom branco

Da Nação Brasileira

Dizem todos os dias

Deixa disso camarada

Me dá um cigarro

(ANDRADE, $1925 / 1971$, p. 89)

Sintetizando, como se dijo, es relevante por un lado, poder articular la perspectiva teórica desde las Ciencias Sociales con la cultura, la sociedad y el arte del mundo luso-brasileño. Y por otro lado, evidenciar que no es posible concebir a la lengua en abstracto ni como una cuestión estanca. Por ello, a lo largo de la materia quedan de manifiesto las tensiones y variaciones que se presentan y cómo su aprendizaje y su enseñanza deben insertarse en un universo más amplio.

Por último, consideramos que articular las teorías y conceptos vistos en clase con análisis específicos de la historia y la cultura luso-brasilera resulta enriquecedor, productivo y necesario para aprehender los contenidos propuestos. La dinámica de clase y los temas abordados también han despertado el interés por querer indagar la situación económica, cultural, social y política cotidiana de Brasil por parte del propio alumnado. Por ejemplo, a partir del acceso personal a notas periodísticas de actualidad, los estudiantes han hablado de la problemática de discriminación racial y religiosa que sufren, aun hoy, sectores de la sociedad brasilera. Estas fuentes, consultadas principalmente por alumnos brasileros, son traídas al contexto áulico y puestas a discusión entre todos, siempre a la luz de los contenidos vistos en esa clase. En síntesis, se trata entonces de encontrar para cada contenido el mejor método de enseñanza y de tener presente el valor social de dicho contenido, haciendo eje en la comprensión y en favorecer un proceso reflexivo de lo que se aprende (LITWIN, 2010).

\section{REFLEXIONES FINALES}

En este artículo se propuso abordar una perspectiva para pensar y aplicar contenidos vinculados con la cultura en la enseñanza-aprendizaje de una lengua extranjera. Partiendo de la perspectiva que concibe a la competencia comunicativa desde un punto de vista sociolingüístico y pragmático, en este trabajo se avanzó 
más allá, para considerar la puesta en práctica de la enseñanza de contenidos específicos de cultura y sociedad en una materia separada de las de lengua. Así, teniendo en cuenta la estrecha relación entre lengua y cultura, se presentó el modo particular en que es posible incorporar contenidos de cultura en la enseñanza de lenguas extranjeras a través de materias que tengan como punto de partida las Ciencias Sociales, situación no siempre frecuente pero que consideramos fructífera y beneficiosa.

Para ello se realizó una reflexión que involucró de modo conjunto la teoría y la explicitación de los presupuestos de los cuales se partió, se enfatizó la importancia de la relación entre lengua y cultura, considerada aquí como un "binomio" en el cual sus términos son interdependientes y entre interculturalidad y educación en el marco de una concepción democrática que respete y no anule las diferencias en el contexto de la enseñanza de lenguas extranjeras.

Con respecto al caso estudiado en este artículo, se analizó la propuesta teóricometodológica de la materia "Cultura y sociedad" del Profesorado en Portugués de la Universidad Nacional de La Plata, donde se dictan contenidos ligados con los procesos sociales y culturales tanto a nivel teórico como de implementación concreta de aspectos ligados a Brasil. Para ello, se señalaron algunos de los puntos de partida de la mirada que prevalece en dicha asignatura, como la consideración de cultura y la sociedad como procesos humanos construidos históricamente y en permanente cambio, la mirada crítica sobre el orden social y la concepción del "otro" en función de su diferencia (étnica, social, de género, entre otras).

Asimismo, en términos didácticos, se expuso la metodología propuesta de la materia analizada, resaltando algunas características tales como la concepción de guiar el proceso de aprendizaje de los alumnos y donde se genere un diálogo entre docente y alumnos. Estos últimos son capaces de reflexionar, hipotetizar y producir conocimiento en el contexto áulico, donde se tienen especialmente en cuenta sus conocimientos, experiencias y saberes previos. Además, se señaló el carácter audiovisual dado a las clases, a través de la incorporación de recursos tales como videos, imágenes y otras fuentes como documentos y recortes periodísticos.

Se describieron cuatro ejemplos de cómo se llevó a cabo la experiencia de esta materia, especialmente en la metodología de anclar los contenidos teóricos con procesos socio-culturales de Brasil. De este modo, se indagó de qué modo habían sido llevados a cabo los temas relacionados con racismo, religiosidades, microfísica del poder y modernismo en Brasil, se presentó el abordaje de cada uno, se mostraron algunos de los recursos utilizados y aportes realizados por los alumnos. 
Los resultados obtenidos en el dictado de la materia considerada, "Cultura y sociedad", han sido un alto involucramiento de docentes y alumnos en el proceso de enseñanza-aprendizaje, con gran participación del estudiantado tanto en el contexto áulico como fuera de él en actividades como preparación de clases especiales y búsqueda de información y ejemplos. Además, fue posible corroborar la motivación que generó en los alumnos la vinculación entre temas teóricos, aplicación concreta a casos de Brasil, bibliografía en portugués y recursos audiovisuales o fuentes. La combinación de estos elementos, no sólo despertó el interés, sino que generó momentos de reflexión y pensamiento crítico, tanto de los temas generales, como sobre la propia cultura y la de la lengua objetivo. En todo el proceso, el papel de las docentes como guías y acompañando la decodificación de los contenidos, favoreció el logro de los objetivos planteados.

La potencialidad del enfoque asumido en la materia "Cultura y sociedad" del Profesorado de Portugués ha permitido abrir el diálogo con y entre los estudiantes, repensando prácticas propias y ajenas. En este sentido, comprender los principios generales que sostienen que las lenguas y los discursos son prácticas sociales que se construyen en el marco de una cultura histórica que impone sus reglas, sentidos y significaciones, será fundamental para que los futuros profesores de lengua extranjera construyan un pensamiento crítico, históricamente situado, así como para que puedan reflexionar tanto sobre las propias prácticas y sobre una cultura y sociedad diferentes de la suya. Asumir un posicionamiento que se detenga en temas como los que se presentan en el programa de la materia, implica también ser capaces de indagar y poner en cuestión situaciones naturalizadas por el sentido común y la vida cotidiana. Esto será particularmente importante como agentes que pongan en contacto dos lenguas y culturas diferentes, donde las prácticas de cada una tendrán una dimensión histórica y social particular.

Para finalizar, es importante mencionar el documento de la Dirección de Modalidad de Educación Intercultural (Provincia de Buenos Aires, Argentina), elaborado en el año 2007 por Thisted. Si bien corresponde a la Dirección General de Cultura y Educación de la provincia de Buenos Aires, sus contenidos exceden la enseñanza secundaria, pues hace hincapié en la promoción de una perspectiva política, social y educativa intercultural. El documento realza la necesidad de construir una perspectiva intercultural, lo cual supone, entre otras cuestiones, construir diseños curriculares que incluyan la interculturalidad como perspectiva, como estrategia y contenido (THISTED, 2007). Es decir, se propugna un enfoque que revise los estereotipos y repertorios homogeneizantes para reconocer a los propios alumnos como sujetos inscriptos en identificaciones de género, etnia, clase 
social, cultura y otros posibles. Asimismo, contempla el uso en el aula de recursos y materiales creativos e innovadores y en lo pedagógico y curricular parte de análisis de contextos, procesos de interacción social en la construcción de conocimientos y de espacios conjuntos de reflexión. En base a la experiencia de la cátedra, esta perspectiva es no solo útil sino también beneficiosa, en tanto la necesidad de pensar de forma articulada la lengua y la cultura contribuye a formar una mirada crítica, reflexiva e integral, con una impronta intercultural, sobre los procesos históricos, sociales y culturales del mundo.

\section{REFERENCIAS BIBLIOGRÁFICAS}

ALMEIDA, R. de; MONTEIRO, P. (2001) Trânsito Religioso no Brasil. São Paulo em Perspectiva, v.15, $\mathrm{n}^{\circ} 3$, pp. 92-101.

ANDRADE, O. D. (18 de março 1924) Manifesto da Poesia Pau - Brasil. Correio da Manbã, Rio de Janeiro, s/p.

ANDRADE, O. D. (1928) Manifesto Antropófago. Revista de Antropofagia, n 1, pp. 3-7.

ANDRADE, O. D. (1971) Poesias Reunidas. Rio de Janeiro: Civilização Brasileira.

BUGNONE, A. L. (2015) Lengua, cultura e interculturalidad en la enseñanza de lenguas extranjeras (En línea). VIII COLOQUIO PELSE, Universidad del Litoral, Santa Fe. Disponible en: http://www.memoria.fahce.unlp.edu.ar/trab eventos/ev.4124/ ev.4124.pdf. Acceso el: 10 mai. 2016.

BUGNONE, A. L y CAPASSO, V C. (2015) El trabajo sobre el binomio lengua/cultura y la interculturalidad para la enseñanza-aprendizaje de una lengua extranjera. VII ENCUENTRO ACADÉMICO DEL DEPARTAMENTO DE LENGUAS Y LITERATURAS MODERNAS, Universidad Nacional de La Plata, La Plata.

BHABHA, H. (2002) El lugar de la cultura. Buenos Aires: Manantial.

BOAVENTURA, M. E. (1986) O projeto Pau Brasil: nacionalismo e inventividade. Remate de Males, v. 6, pp. 45-52.

BOURDIEU, P. (1983) Sociologia. São Paulo: Ática.

DAMATTA, R. (1984) O que faz o brasil, Brasil? Rio de Janeiro: Rocco.

DIEZ, M L. (2004) Reflexiones en torno a la interculturalidad. Cuadernos de Antropología Social, $n^{\circ} 19$, pp. 191-213.

DOS REIS BATISTA, M. (2008) Considerações acerca do intercultural no ensino do Português brasileiro para falantes de outras línguas: Por que e para quê?. II FÓRUM DE LÍNGUAS ESTRANGEIRAS, Faculdade de Letras Estrangeiras Modernas, Instituto de Letras e Comunicação, Universidade Federal do Pará, Belem.

FLEURI, R. M. (2003) "Intercultura e educação". Revista Brasileira de Educação, n² 23, pp. 16-35. 
FOUCAULT, M. (1984) Microfísica do poder. Rio de Janeiro: Edições Graal.

FOUCAULT, M. (1987) Vigiar e punir: nascimento da prisão. Petrópolis: Vozes.

FOUCAULT, M. (1995) O Sujeito e o poder. In: Dreyfus, H. L.; Rabinow, P.; Carrero, V. P. Michel Foucault, uma trajetória filosófica: para além do estruturalismo e da hermenêutica. Rio de Janeiro: Forense Universitária, pp. 231-249.

GARCÍA BENITO, A. B. (2009). La competencia intercultural y el papel del profesor de lenguas extranjeras. El profesor de español LE-L2: Actas del XIX Congreso Internacional de la Asociación para la Enseñanza del Español como Lengua Extranjera (ASELE): Cáceres, 24-27 de septiembre de 2008, pp. 493-506.

GEERTZ, C. (1973) A Interpretação das culturas. Rio de Janeiro: Zahar.

GUimARÃES, A. (2004) Preconceito de cor e Racismo no Brasil. Revista de Antropología. V.47, n¹, pp. 9-43.

LITWIN, E. (2010) Corrientes Didácticas contemporáneas. Buenos Aires: Paidós.

MIQUEL, L. (1999). El choque intercultural: reflexiones y recursos para el trabajo en el aula. Carabela. $n^{\circ} 45$, pp. 27-46.

NASCIMENTO, A. (2010) Candomblé e Umbanda: Práticas religiosas da identidade negra no Brasil. Revista Brasileira de Sociologia da Emoção. v. 9, n² 27, pp. 923-944.

ORTIZ, R. (2006) Cultura Brasileira e Identidade Nacional. São Paulo: Brasiliense.

PIERUCCI, A. F. (2004) Bye bye, Brasil: o declínio das religiões tradicionais no Censo 2000. Estudos Avançados. v.18, n 52, pp. 17-28.

RIBEIRO, D. (1995) O povo brasileiro: evolução e o sentido do Brasil. São Paulo: Companhia das Letras.

RIVA DE ALMEIDA, M. (2011) Um olbar intercultural na formação de professores de línguas estrangeiras. Tese Doutorado em Letras. Univer-sidade Federal do Paraná, Curitiba.

THISTED, S. (2007) Interculturalidad como perspectiva política, social y educativa. Provincia de Buenos Aires: Dirección de Modalidad de Educación Intercultural, Subsecretaría de Educación, Dirección General de Cultura y Educación.

WILLIAMS, R. (2003) La larga revolución. Buenos Aires: Nueva Visión.

WILLIAMS, R. (2007) Palavras-chave: um vocabulário de cultura e sociedade. São Paulo: Boitempo.

\section{Fuentes citadas:}

INSTITUTO BRASILEIRO DE GEOGRAFIA Y ESTATÍSTICA. (2010) Questionário básico, Censo Demográfico 2010. Disponible en: http://censo2010.ibge.gov.br/images/pdf/ censo2010/questionarios/questionario basico cd2010.pdf. Acceso el: 01 mai. 2016.

MARTÍN, M. (2015) A política que barra negros e pobres e ameaça a democracia da areia no Rio, El País. Disponible en http://brasil.elpais.com/brasil/2015/08/27/ internacional/1440710239 607074.html. Acceso el: 01 mai. 2016. 
ONU NAÇÕES UNIDAS NO BRASIL. Especial: A intolerância contra as religiões de matrizes africanas no Brasil [vídeo]. Disponible en https://www.youtube.com/watch?v=tSbl2LwFB1s. Acceso el: 01 mai. 2016.

UNIVERSIDADE FEDERAL DA BAHIA. Especial Novembro Negro - Religiōes de matriz africana: unidade e diversidade [vídeo]. Disponible en https://www.youtube.com/ watch?v=kq8g663WCT4. Acceso el: 01 mai. 2016.

Recebido: 07/06/2016

Aceito: 22/09/2016 